\title{
Acute Epididymo-Orchitis: a Rare Cause of Delirium in Demented Patient
}

\section{Ali SH}

Geriatric Medicine \& Gerontology department, Faculty of Medicine, Ain Shams University, Cairo, Egypt.

\begin{abstract}
Delirium is a common presentation in elderly with diverse underlying causes. This elderly man presented with disturbed level of conscious level with no apparant precipitating factor. After thorough investigations and with substantial help from the caregiver, acute epididymo-orchitis was revealed as an unusual reason of deliriumn early and a quick identification of dementia is desirable to improve the overall care to the affected persons in the developing countries
\end{abstract}

\section{Background:}

This case is presented with hyperactive delirium. Delirium is acute brain failure. It is a multifactorial syndrome (1) and preventable in $30-40 \%$ of cases (2). Precipitating factors varied across patient populations. In medical patients, Polypharmacy, psychoactive medication use, and physical restraints were the leading factors while abnormal laboratory values were risk factors in all populations, convening a high risk $(3,4)$. Clinicians should remain aware that both common and rare conditions might present with delirium. The purpose of this report is to provide a syndrome of delirium with rare underlying cause so that we could not miss in other geriatric delirious patients.

\section{The case description:}

67 years old man was known as diabetic, hypertensive, benign prostatic hyperplasia and vascular dementia. He presented with delirium (acute disturbance in conscious level, fluctuating with agitation) as stated by his son. Vital signs were: blood pressure $119 / 60$, pulse $80 \mathrm{~b} / \mathrm{m}$ and regular, temperature 36.4 and saturation $95 \%$. Physical examination: male patient, average built, disoriented and fidgeting. Chest, cardiac, abdominal and neurologal examination were unremarkable. There was no pyrexia or urinary symptoms and negative urine dipstick. All other blood tests were normal. Total leucoctic count was $8.34 \times 10^{9} / \mathrm{L}$. ECG: normal sinus rhytm. Abdominal U/S was normal except for thick wall gall bladder wall. When all results came normal and it did not reveal any underlying cause delirium, the son stated that he appreciated small swelling in left testis. Reexamination is done again. Moderate increase in left testis size with swelling was revealed. Testicular U/S showed (figure 1): mild right side hydrocele, left testis is enlarged, moderate hydrocele and thick wall seminal vesicle, the epididymis and testis appears hypoechoic. Ciprofloxacin was prescribed and the patient improved and sent home 5 days later.

\section{Discussion:}

Acute epididymo-orchitis is an acute inflammatory disease of both the epididymis and ipsilateral testis. It most often presents unilaterally and occurs because of a specific or nonspecific urinary tract infection (urethritis, prostatitis, or cystitis) that seeds to the epididymis and testis through the lymphatic vessels or ductus deferens. Clinical signs such as fever, elevated CRP and positive urine dipstick test for leucocytes and nitrites [(5) are suggestive of epididymo-orchitis but all signs were absent in this case. Most commonly, it is the epididymis that first evolves with a proliferative inflammatory process, and then the inflammation extends to the testis. In the exudative inflammatory phase, a serous fluid collects 
around the testis and causes enlargement of scrotum - a reactive hydrocele. Acute epididymo-orchitis is always accompanied by a subfebrile or febrile temperature and intense scrotal pain, which may radiate up along the funiculus spermaticus. Diagnostic procedures include physical examination, standard laboratory tests, scrotal ultrasound investigation, and microscopic examination of urethral discharges if they are present. Classic palpation of the scrotum is the first method of diagnosing acute epididymo-orchitis. This technique allows establishing the anatomic structure of the scrotal organs, characteristics and grade of their inflammatory changes, differentiation between epididymis and testis, and their local softening (malacia) as a consequence of purulent destruction.

Scrotal ultrasound investigation is helpful in diagnosing acute epididymo-orchitis. This method makes it possible to evaluate the condition of the epididymis and testis - their structure and presence or absence and size of abscesses and hydrocele $(6,7)$. Of high value in the differential diagnosis of acute epididymo-orchitis is color doppler imaging of the scrotum. It has proven to be quite helpful in evaluating the scrotal contents for the presence of inflammation and associated complications $(8,9)$.

\section{Conclusion:}

This case report demonstrates a rare cause of delirium in demented patient. Acute epididymo-orchitis presented here atypically with no fever, normal total leukocytes count but with sensible testicular swelling. Caregiver is important informant in dementia cases.

\section{References}

1. $[\mathrm{M}$ Inouye SK, Charpentier PA. Precipitating factors for delirium in hospitalized elderly persons. Predictive model and interrelationship with baseline vulnerability. JAMA. 1996 Mar 20;275(11):852-7.

2. Marcantonio ER, Flacker JM, Wright RJ, Resnick NM. Reducing delirium after hip fracture: a randomized trial. J Am Geriatr Soc. 2001 May;49(5):516-22.

3. Marcantonio ER, Flacker JM, Wright RJ, Resnick NM. Reducing delirium after hip fracture: a randomized trial. J Am Geriatr Soc. 2001 May;49(5):516-22.

4. Marcantonio ER. Postoperative delirium: a 76-year-old woman with delirium following surgery. JAMA. 2012 Jul 4;308(1):73-81.

5. Chiang MC, Chen HW, Fu RH, Lien R, Wang TM, Hsu JF. Clinical features of testicular torsion and epididymo-orchitis in infants younger than 3 months. J Pediatr Surg. 2007;42:1574-7.

6. See WA, Mack LA, Krieger JN. Scrotal ultrasonography: A predictor of complicated epididymitis requiring orchiectomy. $J$ Urol. 1988;139:55-56.

7. Mevorach RA, Lerner RM, Dvoretsky PM, et al. Testicular abscess: Diagnosis by ultrasonography. J Urol. 1986;136:1213-1216.

8. Süzer $\mathrm{O}$, Ozcan $\mathrm{H}$, Küpeli $\mathrm{S}$, et al. Color Doppler imaging in the diagnosis of the acute scrotum. Eur Urol. 1997;32:457-461.

9. Herbener TE. Ultrasound in the assessment of the acute scrotum. J Clin Ultrasound. 1996;24(8):405-421.

\section{Figure 1:}

Scrotal ultrasound shows mild right side hydrocele, left testis is enlarged, moderate hydrocele and thick wall seminal vesicle, the epididymis and testis appears hypoechoic.

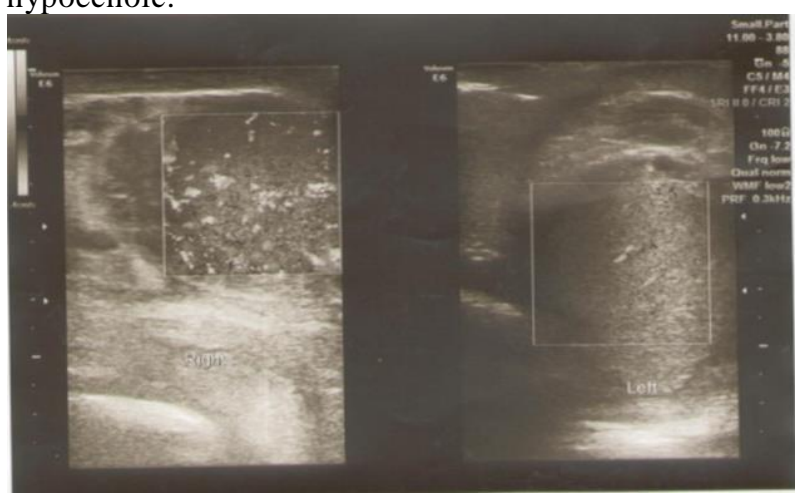

